\title{
As redes pedagógicas materializadas em narrativas docentes
}

\author{
Pedagogical networks materialized as teachers' narratives
}

Practicas pedagógicas materializadas en narrativas docentes

\author{
JANAINA CARRASCO CASTILHO (Da \\ Maria AuXILIAdora Bueno ANDRADE MegID (D) b
}

\section{Resumo}

O objetivo deste artigo é apresentar uma análise de uma rede de parceiros e apoios docentes, estabelecida a partir de narrativas sobre as práticas pedagógicas realizadas por professoras atuantes em uma escola pública no decorrer do ano de 2018. Insere-se no âmbito de uma pesquisa mais ampla de doutorado que, a partir de um estudo de caso, investigou as relações de colaboração numa escola pública municipal de Ensino Fundamental I, localizada em uma cidade do interior do estado de São Paulo. Como procedimentos metodológicos, realizamos um estudo bibliográfico sobre a organização social em redes e uma pesquisa de campo, acompanhando um grupo de dez professores em atuação profissional. Foram realizadas entrevistas narrativas que abordaram as práticas pedagógicas realizadas nessa escola. A análise foi efetivada a partir de eixos temáticos que emergiram dos elementos fornecidos pelas narrativas, com os quais estabelecemos diálogos ancorados no aporte teórico do estudo bibliográfico. Os resultados revelados mediante a análise das narrativas sobre essas práticas pedagógicas evidenciaram a articulação dos professores com parceiros pertencentes a diferentes espaços e tempos sociais, com os quais estabeleceram laços por meio de experiências vividas, não somente aquelas do interior da escola, mas que extrapolam os territórios de atuação profissional. A partir dessas evidências, podemos considerar que os diferentes interlocutores que compõem a rede social do professor, e com ele

\footnotetext{
a Pontifícia Universidade Católica de Campinas (PUC-Campinas), Campinas, SP, Brasil. Doutora em Educação, e-mail: janacarasco@yahoo.com.br

b Pontifícia Universidade Católica de Campinas (PUC-Campinas), Campinas, SP, Brasil. Doutora em Educação, e-mail: dmegid@puc-campinas.edu.br
} 
estabelecem relações de trocas, potencializadas pelos avanços tecnológicos nos meios de comunicação, são os responsáveis por promover a continuidade da formação profissional docente.

Palavras-chave: Redes sociais. Desenvolvimento profissional. Práticas pedagógicas.

\section{Abstract}

The purpose of this article is to present an analysis of a network of partners and teacher support based on the narratives about pedagogical practices made by teachers at a public school during the year of 2018. It is part of a broader doctorate research that, based on a case study, investigated the collaboration relationships of an Elementary I municipal public school in the countryside of São Paulo. As methodological procedures, a bibliographical study about the social organization in networks was carried out, as well as a field research that followed up on ten teachers acting in professional settings. Narrative interviews were conducted to discuss the pedagogical practices that took place in that school. The analysis was performed from thematic axles extracted from the elements provided by the narratives, which supported the connections with the bibliographical study. The results reached through the analysis of the narratives about such pedagogical practices show the articulation between teachers and partners that belong to different social spaces and times, with whom connections are built through their experiences, not only those inside the school but also those beyond professional settings. Based on the evidence, it was possible to consider that the different interlocutors that comprise a teacher's network - with whom the teacher establishes an exchange relationship boosted by technological means of communication - are responsible for promoting the continuity of the teacher professional education.

Keywords: Social Media. Professional Development. Pedagogical Practices.

\section{Resumen}

El objetivo de este artículo es presentar el análisis de una red de asociados y apoyos docentes establecida a partir de narrativas acerca de prácticas pedagógicas realizadas por profesoras que actuaron en una escuela pública a lo largo del año 2018. Se inserta en el ámbito de una investigación más amplia de doctorado que, a partir de un estudio de caso, investigó las relaciones de colaboración en una escuela pública municipal de Enseñanza Elemental l, ubicada en una ciudad en el interior del estado de São Paulo. Como procedimientos metodológicos, se hicieron un estudio bibliográfico sobre la organización social en redes y una investigación de campo donde se acompañó un grupo de diez profesores en actuación profesional. Se hicieron entrevistas narrativas que abordaron las prácticas pedagógicas realizadas en esta escuela. El análisis se efectivó a partir de los ejes temáticos que emergieron desde los elementos proveídos por las narrativas, con los cuales se establecieron diálogos anclados en el aporte teórico del estudio bibliográfico. Los resultados revelados por medio del análisis de las narrativas 
sobre esas prácticas pedagógicas evidenciaron la articulación de los profesores con asociados pertenecientes a diferentes espacios y tiempos sociales, con los cuales se establecieron lazos por medio de experiencias vividas, no solamente aquellas en el interior de la escuela, sino que las que extrapolan los territorios de actuación profesional. A partir de esas evidencias, podemos considerar que los diferentes interlocutores que componen la red social del profesor, y que con él establecen relaciones de cambio, potencializadas por los avances tecnológicos en los medios de comunicación, son los responsables de promover la continuidad de la formación profesional docente.

Palabras clave: Redes Sociales. Desarrollo Profesional. Prácticas Pedagógicas.

\section{Introdução}

O homem, como ser social, desde épocas remotas utiliza-se da linguagem para interagir e comunicar-se com seus pares. A aproximação e a convivência em grupos, mais do que uma opção, mostra-se como uma necessidade de sobrevivência, evolução e fortalecimento da espécie.

Na convivência em grupos há a aproximação e o fortalecimento de laços que são estabelecidos visando sanar as demandas internas. No entanto, com a evolução da sociedade, o isolamento em grupos restritos passou a ser inviável, diante da interdependência global vigente na sociedade contemporânea.

A ampliação na interação entre diferentes grupos intensificou a dinâmica nas relações humanas, atingindo os diferentes cantos do planeta. Com o uso da internet, grupos e indivíduos de diferentes locais do planeta podem comunicar-se, estabelecendo conexões entre si. Dessa forma, a sociedade tece uma rede de interações, constituída tanto por laços advindos de relações mais íntimas e fortes, nos núcleos familiares e afins, como por laços fracos e mais frágeis, resultantes de aproximações ocasionais e fluidas.

Considerando essa dinâmica interativa, no presente artigo e com o foco no ambiente educativo escolar, objetivamos identificar, em narrativas de professores de Educação Básica atuantes em uma escola de Ensino Fundamental, elementos que revelem os processos de construção de suas práticas pedagógicas diárias, considerando a rede social com a qual estabelecem relações constantes e contínuas de trocas.

Buscamos, no decorrer de suas trajetórias profissionais, por meio de encontros e desencontros de informações, quais são as posturas reveladas, as orientações e 
regulamentações que indicam como potenciais para o desenvolvimento profissional nesse processo dialógico.

Compreendendo a potencialidade do desenvolvimento docente como construção autônoma e investigativa frente à realidade, propusemos aos participantes desta pesquisa que nos contassem sobre suas práticas pedagógicas realizadas durante o ano letivo e sobre as parcerias estabelecidas para a efetivação dessa empreitada, expressando suas intenções, desafios e reflexões diante das experiências vividas.

As narrativas produzidas pelos professores têm representado um instrumento potente no sentido de auxiliar nos processos formativos desses profissionais e, tomando-as por material empírico nas pesquisas educacionais, torna-se possível ao participante expor e materializar, seja na forma escrita, seja na forma oral e a partir de uma ótica individual, os diversos elementos relacionados ao cotidiano escolar e às práticas pedagógicas.

Ao propormos a análise de narrativas docentes nesta pesquisa, visando identificar as redes formativas dos professores por meio dos laços por eles estabelecidos na dinâmica social, pretendemos apresentar possibilidades de reflexões aos que elaboram políticas de formação docente, pautadas em incentivos para ampliação do repertório científico e cultural e no fomento à divulgação e à socialização de práticas promissoras entre os profissionais em atuação. Com isso, entendemos como possível aprimorar as redes educativas e fortalecer as bases para o desenvolvimento autônomo e investigativo do professor.

\section{As redes}

O conceito de redes emergiu do pensamento sistêmico como forma de compreender a ciência. Inicialmente, foi observado em organismos vivos, depois, em biomas e nos ecossistemas ecológicos (CAPRA, 2014). Nas últimas décadas, o conceito de redes passou a ser utilizado para pensarmos os aspectos da vida social e, de maneira ampla, a conexão existente em toda a sociedade, por meio do pensamento complexo (MORIN, 2008). 
As redes assumem diversas formas. Elas podem ser verificadas tanto no plano coletivo, na relação entre os seres vivos e o ambiente, como na organização individual de cada ser, como um macrossistema formado por órgãos e células.

As redes sociais, especificamente, formam-se pela articulação de pessoas ou grupos em processos de comunicação, relações afetivas ou distribuição de informações, tendo sido potencializadas pelos avanços nas tecnologias da informação e comunicação (FUSER, 2003).

Tecnicamente, as redes são compostas por nós, os quais podem ser representados por círculos. Os nós são as pessoas ou os grupos que almejam um objetivo comum, responsáveis pelo tamanho da rede. Os laços ou arestas, representados por linhas, conectam dois ou mais nós. Os fluxos existentes nessas conexões indicam a direção do vínculo, podendo ser unidirecional, bidirecional ou, na ausência de fluxos, implicar a inexistência de vínculos, configurando, portanto, um nó isolado na rede (FIALHO, 2014).

Já o funcionamento das redes ocorre por meio de uma triangulação, de modo que os nós que a compõem não se enfrentam quando em contradição. Nesse caso, esses conteúdos interagem com um $3^{\circ}$ nó, depois com um $4^{\circ}$ e outros, sucessivamente. Num processo assim delineado são desalojadas as contradições e transformadas as posições fixas, num fluxo intenso e dinâmico (FUSER, 2003).

De modo geral, as redes são irregulares, flexíveis, capazes de modificarem-se, moverem-se, fazerem-se e refazerem-se continuamente, sendo constituídas horizontalmente. Ao tratarmos de redes sociais, podemos afirmar que propiciam um clima de respeito, confiança e intercâmbio e, de maneira fundante, mantêm-se abertas em relação à aprendizagem (MONTAÑO; MARTINEZ; TORRE, 2017).

Entre os componentes das redes, os laços podem fornecer informações importantes, conforme as características que apresentam entre si. De acordo com Portugal (2007), as arestas ou laços nas redes sociais podem ser caracterizados como fortes ou fracos, positivos e negativos, ativos, passivos e mistos.

Sobre os laços fortes e fracos, Kaufman (2012), estudioso sobre redes de relacionamento, desenvolveu pesquisas diferenciando e caracterizando cada um desses laços. Inicialmente, o autor colocava em evidência a importância dos laços fortes na estabilidade e segurança da vida dos indivíduos. Posteriormente, retomou 
os estudos sobre os relacionamentos em redes e enfatizou a importância dos laços fracos aí existentes, como responsáveis pelas inovações e articulação dos indivíduos às experiências e formações diversas. De acordo com seus estudos, se houver ausência de laços fracos nas redes, há a tendência ao isolamento e confinamento em núcleos restritos e estáveis (GRANOVETTER, 1983, apud KAUFMAN, 2012).

Agier (2011) analisou as redes de sociabilidade que partiam de um núcleo específico e territorializado, constituído por laços fortes de confiança e reciprocidade existentes na família, na vizinhança, nos grupos de trabalho, que se articulavam e se alargavam em redes multilocais. Ele observou que, apesar de as redes de sociabilidade permitirem a interação do microssocial com as esferas das macroestruturas sociais de representação de identidades coletivas, os laços permaneciam ligados aos valores relacionais de origem (AGIER, 2011).

Apesar da importância dos laços fracos na ampliação de perspectivas e inovações, as identidades apresentam resistências às transformações, por voltarem-se às redes de laços fortes em busca de segurança e sustentação.

Já as redes educativas escolares baseiam-se em um conceito de formação sustentável para toda a comunidade educativa. O conhecimento produzido nelas, visando a essa formação sustentável, deve assemelhar-se ao conceito de inteligência coletiva apresentado por Lévy (2003). Tal inteligência mobiliza as diferentes competências, compreendendo-as em suas multiplicidades, e deve ser distribuída entre todos promovendo a desterritorialização dos saberes, mantendo interligações dos diferentes espaços geográficos.

Dessa maneira, o trabalho em redes educativas deve ser coordenado e consensuado, o que aumenta a capacidade de atuação dos professores, porque promove atuações colaborativas, que aumentam o sentido de pertencimento à comunidade escolar e fortalecem a sensação de segurança profissional. Para Montaño, Martinez e Torre (2017, p. 653), ao incorporar informações e construir novos significados compartilhados nas redes, os professores passam a substituir práticas de atuação individuais e solitárias por trabalhos coletivos e integrados.

Diante do potencial formativo verificado nas redes educativas, elas passaram a ser utilizadas por sistemas e órgãos de controle, sob concepções distintas: a utilitarista, com intuito de intervir na realidade e obter determinados resultados, e a 
concepção analítica, que busca compreender melhor as características das redes numa abordagem estrutural. Há sistemas educativos que tentam implantar as redes educacionais em suas reformas educativas, propondo regras e objetivos pensados de fora para dentro da rede, visando atender a demandas governamentais e rompendo com a concepção de organização horizontal própria das redes (LIMA, 2015). Neste artigo, evidenciaremos as redes constituídas a partir de demandas dos próprios indivíduos e dos grupos que delas participam, em redes de relacionamento constituídas espontaneamente.

Há redes educativas formais, organizadas com a intenção do alcance de determinados objetivos, e redes informais, cuja existência é desencadeada espontaneamente, a partir de demandas e necessidades de grupos ou indivíduos. As redes informais agem de maneira peculiar às estruturas de poder e antecipam-se às outras, de modo a representarem motores propulsores de mudanças (FUSER, 2003).

Para a pesquisadora Alves (2017), que estuda o cotidiano da Educação, as redes educativas em sua multiplicidade permitem a coexistência do binômio prática e teoria, desencadeando processos educativos dialógicos com potencial dinâmico, contínuo e constante, capaz de acompanhar o ritmo dos acontecimentos no cotidiano das relações escolares.

\section{Narrativas}

A linguagem é um fator que constitui o homem por meio da sua função social e comunicativa (VIGOTSKY, 2007), de acordo com a concepção sociointeracionista. Nesse processo de expressão e comunicação, o ser humano constrói-se e constrói o mundo, criando signos e significados próprios dos seus grupos sociais, na interação com o contexto, produzindo repertórios culturais.

As descobertas, as experiências vividas e os conhecimentos acumulados pelas pessoas são deixados para os seus descendentes por meio do registro. A geração seguinte, por sua vez, contribui com esse legado, ampliando-o. Configuram-se por esse movimento relações tanto horizontais, de comunicação entre pessoas pertencentes a um mesmo momento histórico, como verticais, entre sujeitos de 
tempos históricos distintos, que se comunicam por meio dos registros (AGUIAR, 2004).

Antes do surgimento da escrita, quando os processos comunicativos da sociedade eram baseados na cultura oral, as relações verticais aconteciam de forma mais lenta, pois dependiam da interação entre os mais velhos e os mais novos, para que fossem socializados os conhecimentos construídos pela humanidade. Nesse período da história, os mais velhos, de acordo com Lévy (2008), eram as principais fontes do saber prático, mítico e de rituais. Sua morte poderia ser comparada à queima de uma biblioteca, numa sociedade letrada.

Em nossa vida cotidiana, linguagens verbais e não verbais estão presentes e são processadas pelo cérebro de formas distintas. A língua falada ou escrita, enquanto linguagem verbal (palavra), envolve atividades lógicas, racionais e sistematizadas, enquanto as diversas linguagens não verbais, como a música, as cores, as formas, a dança, não emitem mensagens objetivas, mas expressam-se na sua totalidade de forma metafórica e simbólica (AGUIAR, 2004).

Apesar dessa distinção entre as formas de linguagem, durante o processo de comunicação, elas ocorrem simultaneamente e complementam-se. Ou seja, a linguagem articulada, que possibilita a existência das línguas, é complementada pela linguagem não verbal expressa por imagens sensoriais: visuais, auditivas, sinestésicas, olfativas e gustativas.

À medida que o ser humano passa a verbalizar, torna-se apto a produzir textos, definidos como segmentos verbais que funcionam como unidades de sentido na intercomunicação humana (AZEREDO, 2011). De maneira ampla, podemos entender como textos todos os objetos culturais verbais ou não que remetam a um código cultural capaz de expressar sentido, como a moda, a literatura, o artesanato, jornais, entre outros meios (AGUIAR, 2004).

Com o avanço das tecnologias e as transformações da sociedade, a comunicação entre as pessoas passou por diversas mudanças em relação à forma e ao conteúdo. O ritmo na veiculação das informações foi acelerado, os acontecimentos são noticiados em tempo real e as mídias centralizam os processos comunicativos. Em decorrência disso, ao final do século XX, com o advento da Internet, aconteceu a revolução da linguagem textual (CASTELLS, 2016). 
Se com o surgimento da escrita um sentido de linearidade aos processos comunicativos orais se apresenta, com a inserção da escrita no ciberespaço a linearidade foi alterada pelas múltiplas possibilidades oferecidas pelo hipertexto.

Apesar de apresentar alguma linearidade, não rompendo completamente com a organização das línguas utilizadas pela humanidade que se estruturam pela sintaxe, semântica e pragmática, o hipertexto é mais flexível quanto à hierarquização nos aspectos visuais, discursivos e quanto às unidades de informação (XAVIER, 2005).

No hipertexto, o leitor é convidado a assumir uma postura ativa, diferente dos textos tradicionais, utilizando percursos não lineares e não sequenciais, com interfaces interativas nas quais o leitor, a partir de suas escolhas, pode acessar conteúdos diversos, armazenados em uma rede de nós que estão conectados, traçando percursos de interesse próprio e oscilando entre diferentes documentos digitais.

Diante das características do hipertexto, sugerimos um paralelo entre sua forma de organização e a das narrativas, considerando-as um gênero textual, que tem sido utilizado em pesquisas educacionais e nos processos formativos de professores. Apesar de geralmente manter a linearidade na forma da expressão oral ou escrita, a narrativa, quanto ao seu conteúdo, acompanha o percurso subjetivo da memória e das redes semânticas próprias do funcionamento da mente humana.

A produção das narrativas parte, geralmente, de uma proposta relacionada à história de vida ou às práticas docentes e é concebida por caminhos subjetivos e reflexivos em que a memória de fatos, pessoas, sentimentos e sensações relaciona-se aos pensamentos, posturas, teorias e concepções de vida de cada escritor. Sendo únicas, as narrativas relacionam-se à representação da realidade de cada sujeito, e suas características detêm significados a serem explorados pedagogicamente (CUNHA, 1997). O uso das narrativas na apresentação de histórias de vida ou como prática de formação mostra-se muito fértil e propicia o exercício de autorreflexão, contribuindo com o desenvolvimento pessoal e a autovalorização de seus escritores (PASSOS, 2010).

O potencial formativo das narrativas não se limita às elaborações individuais. De acordo com Almeida e Megid (2017), a narrativa pode ser escrita de maneira colaborativa, em ambiente virtual como espaço formativo, com a participação de professores que interagem e discutem sobre aspectos conceituais e pedagógicos. 
São diversos os autores nacionais e internacionais que têm teorizado sobre o uso das narrativas na Educação, entre os quais podemos citar: Clandinin e Connelly (2011), Josso (2004), Galvão (2005), Cunha (1997), Dutra (2002), Fiorentini e Freitas (2007), Passos (2010), Rodrigues e Prado (2015), Almeida e Megid (2017), Abreu (2019), entre outros.

As pesquisas que utilizam as narrativas permitem que os envolvidos participem ativamente na construção investigativa, o que pode revelar características mais democráticas na construção do conhecimento no campo da Formação de Professores.

$\mathrm{Na}$ formação do professor, o saber construído na universidade busca proporcionar o desenvolvimento do conhecimento sistematizado, científico e metodológico. Porém, a formação do professor é mais abrangente e precisa de um saber reflexivo. Um diálogo estabelecido com teorias, práticas docentes dos pares, num movimento dialógico do eu com o coletivo, possibilita ao professor a formação continuada e a construção da identidade profissional (ABREU, 2019).

Em busca de alternativas para uma maior aproximação e apropriação das nuances do cotidiano escolar e de elementos relevantes no desenvolvimento do professor, optamos pelo uso das narrativas como instrumento dessa pesquisa, assumindo as peculiaridades existentes na pesquisa social (ALVES MAZZOTTI, 1998), mas mantendo nos procedimentos metodológicos a rigorosidade e a sistematização próprias da pesquisa científica.

\section{Metodologia}

Nesta pesquisa, optamos por uma abordagem predominantemente qualitativa, por entender que essa é a forma mais adequada de investigação dos fenômenos sociais e que nos permite a análise aprofundada do material obtido, sendo que a incidência de dados quantitativos, que porventura forem observados, será considerada na análise quanto ao seu significado representativo (GIL, 2008).

As narrativas deste artigo representam parte do material empírico de um estudo de caso ocorrido no decorrer do ano letivo de 2018, em uma escola pública 
situada em um bairro com características de periferia, numa cidade do interior do estado de São Paulo, em decorrência de uma pesquisa de doutorado.

Para a produção deste artigo, selecionamos o material empírico constituído por narrativas de dez professores, realizadas no final do ano letivo, sobre suas práticas pedagógicas no contexto em que atuaram profissionalmente.

Esses dez participantes constituem uma amostra de professores da escola, que contava à época com 28 professores. A seleção ocorreu mediante a adesão ao convite à participação voluntária na pesquisa, bem como pela relevância da prática docente, verificada pelo pesquisador no decorrer do ano letivo, quando ocorreram as observações intensivas dessa pesquisa. As narrativas foram produzidas entre os meses de dezembro de 2018 e janeiro de 2020.

Diante das limitações de tempo dos professores e com a finalização do ano letivo, as narrativas foram direcionadas por meio de um roteiro entregue antecipadamente pela pesquisadora aos participantes, e esses textos foram produzidos oralmente pelas professoras, depois transcritos pela pesquisadora.

A seguir, apresentamos o roteiro de perguntas usado pela pesquisadora:

1) Conte sobre sua principal prática pedagógica desenvolvida neste ano, que tenha envolvido parcerias;

2) Quais foram as motivações que desencadearam esse trabalho?

3) Conte como foi o desenvolvimento desse trabalho em parceria.

4) O que a fez aproximar-se desses parceiros de trabalho?

5) No decorrer deste ano, você realizou formações ou teve contato com outras pessoas fora da escola que, direta ou indiretamente, repercutiram em suas ideias, posturas e/ou pontos de vista durante a atuação profissional?

Entre as participantes, uma educadora optou por produzir a narrativa escrita, enquanto outra, atribulada com outras demandas pessoais, decidiu-se pela opção oral. Sobre essa escolha de registro, Cunha (1997) ressalta que as narrativas escritas são mais disciplinadoras do discurso, na comparação com a linguagem oral. Essa diferença pode ser favorável à pesquisa, pois beneficia a espontaneidade no uso das palavras e na construção do enunciado, por oferecer mais dados para análise. Sobre a análise narrativa, Galvão (2005, p. 335) indica que ocorre “a exploração não só do que é dito, 
mas também de como é dito. Olha-se o conteúdo e a forma, podendo examinar-se o modo figurativo como a linguagem é usada".

\section{Análise de dados}

Iniciamos a exposição dos dados a seguir com informações sobre a formação e o tempo de atuação profissional dos professores participantes desta pesquisa. Os nomes usados não são reais e foram sugeridos pelos próprios participantes.

Apresentamos, a seguir, os participantes, todos com ensino superior completo:

Aurora, com 10 anos de magistério, há 6 anos na escola e possui Mestrado; Keylyan, 10 anos de magistério, 5 na escola; Any, 7 anos no magistério e 5 na escola, cursou Especialização; Manu, 8 anos no magistério e 3 na escola, cursou Especialização; MC, 17 anos no magistério e 4 na escola, com Mestrado; Rosa, 18 anos no magistério e 5 na escola, cursou Especialização; Gabi, 3 anos no magistério e 3 na escola; Oswaldo, 4 anos no magistério e 1 na escola, possui Mestrado; Aretusa, 15 anos no magistério e 4 na escola.

A partir da transcrição dos arquivos registrados em áudio, foram realizadas leituras minuciosas com foco nos objetivos da pesquisa. Analisamos as narrativas, reconhecendo, inicialmente, os possíveis elementos constitutivos das redes educativas por meio das indagações: "quem", "como" e "porquê". A partir das incidências das informações encontradas, sugerimos três eixos para organização dos dados: as parcerias, os laços e os tipos de apoio. A análise do conteúdo das narrativas foi realizada a partir do aporte teórico utilizado. A seguir apresentamos excertos das narrativas selecionados tendo em vista sua representatividade em relação aos eixos teóricos.

As entrevistas foram realizadas individualmente, e os áudios foram gravados fora da escola, em virtude do recesso ou férias escolares. No entanto, optamos por agrupar as narrativas por temas nessa apresentação e discussão dos dados, de acordo com a aproximação de elementos relacionados às redes educacionais na escola.

\section{Inclusão}

Neste primeiro bloco, apresentamos excertos das narrativas cujas práticas docentes envolveram o tema da inclusão escolar. 
As professoras que apresentaram narrativas sobre esse tema foram: Aurora, professora de Educação Especial, Keilyan, professora polivalente do $4^{\circ}$ ano, e Any, professora polivalente do $1^{\circ}$ ano.

As participantes tratam de suas práticas, apresentando parceiros com os quais tiveram contato no decorrer do ano letivo. Ao citá-los fazem referência aos laços estabelecidos, ou não, durante a prática docente.

A parceria se estabeleceu no início entre eu, professora titular, e a professora de Ed. Especial, e deu por afinidade, necessidade e, principalmente, na busca do sucesso do aluno. (Keilyan)

Então, sobre minha experiência de parcerias com outros profissionais, como sou professora de Educação Especial, tenho parceria com vários professores em decorrência dos processos de inclusão desenvolvidos nas salas de aula. (Aurora)

E dentre as parcerias que a gente fez durante o ano, um trabalho que foi muito significativo - e é um trabalho que a gente realiza quase todo o ano com os $1^{\circ} \mathrm{s}$ anos - é um trabalho de intervenção com as crianças. Eu realizo a parceria com a professora XXX do outro $1^{\circ}$ ano. Quando a MC estava com o $1^{\circ}$ ano, eu também fazia essa parceria com ela, mas esse ano, a outra professora que estava com a gente no $1^{\circ}$ ano, não se propôs a participar. (Any)

A própria inclusão põe em evidência uma questão de aceitação ao diferente, que por meio da lei torna-se impositiva, sendo a legislação uma parceira com quem são estabelecidos laços unidirecionais, numa instância imediata, como indicado por Kaufman (2012).

Eu acho importante relatar uma experiência que foi muito intensa com uma professora do $4^{\circ}$ ano em relação à inclusão de um aluno com autismo. (Aurora)

Necessitei de parcerias que não interagiam diretamente com o aluno, mas como ele se deslocava bastante pelo ambiente escolar, eu precisava contar com a paciência da inspetora, das faxineiras e outros. (Keilyan)

As parcerias na escola, diante das situações de inclusão, ocorrem pela necessidade diária no convívio, apesar de diversos desencontros que possam surgir, como evidenciado em Fuser (2003).

A presença da gestão e da supervisão nas narrativas representam a parceria e os laços institucionais formais (LIMA, 2015), responsáveis pelo cumprimento 
adequado do trabalho, acompanhamento e interlocução dos parceiros internos e externos à escola.

Apesar da gestão ajudar muito a segurar a barra, acho que assim, talvez a gente deveria ter traçado melhor estratégias de conversa com a família; é lógico que a gente teve episódios de agressão, violência, que a gestão foi fundamental, corria atrás, falava com a família, nos socorria prontamente, mas eu digo, o dia a dia, o cotidiano... Era uma mãe que precisava ouvir que o filho dela tinha um ritmo diferente, não só pedagógico, mas, principalmente, social, emocional e afetivo. (Aurora)

Então, quando fugiu a nossa alçada pedagógica, a gente teve que acionar, sim, a nossa supervisão para nos orientar sobre o que fazer, porque a violência dele poderia atingir outras crianças. Mas foi só um período de susto e, depois, foi uma adaptação, e a gente respirando e tendo esse apoio da supervisora, que foi muito importante, a gente retomou o trabalho de inclusão. (Aurora)

Trata-se de duas práticas distintas de inclusão na mesma escola, mas com cenários diferentes. As professoras Aurora e Keilyan citam mais parceiros em relação à prática docente da professora Any. Quando se referem à constituição de laços, observamos que a professora Any enfatiza a construção de laços fortes com a mãe da criança e com as outras crianças da turma, além do trabalho com a outra professora do primeiro ano (AGIER, 2011). Já a professora Aurora estabelece laços fortes com sua parceira de trabalho, mas utiliza-se, também, de laços fracos em busca de diversos apoios, visando sanar suas necessidades.

Eu acho que também foi muito importante a parceria com outros profissionais. Tive que recorrer muitas vezes a outros professores de Educação Especial mais antigos, com mais experiência, porque era um aluno com bastante dificuldade para inserir na escola. (Aurora)

Foi essencial eu ter feito essas participações em congressos, esses estudos particulares, porque me empoderaram e empoderaram minha fala junto com a professora, no sentido de eu trazer contribuições efetivas, técnicas, teóricas, para a realização do trabalho. (Aurora)

Ao se propor a estabelecer novos laços ou acionar laços mais distantes, a professora Aurora permite uma interlocução sobre a inclusão que extrapola o território escolar, ampliando suas redes de apoio, como indicado por Lévy (2003). Outro fator ocorrido foi a troca da profissional cuidadora, aquela que acompanhava 
o estudante na escola, fora da sala de aula. Essa troca interrompeu o vínculo estabelecido, que precisou ser reconstruído no decorrer do ano letivo.

Estabelecemos parceria, também, com a cuidadora responsável pelo aluno fora da sala de aula. Ela já foi uma parceria com um pouco menos de sucesso, pois contamos com diferentes profissionais. A troca era constante, e assim, até criarmos vínculos e segurança, a parceria não acontecia efetivamente. (Keilyan)

Eu acabei não comentando o trabalho da cuidadora, que é uma profissional maravilhosa. Ele [o aluno] teve duas ao longo do ano, mas as duas foram ótimas, trabalhavam muito em parceria. (Aurora)

A ocorrência citada sobre a troca da cuidadora exemplifica a importância da convivência e da confiança para a aproximação entre os parceiros e o fortalecimento de laços. Nessa situação extrema que envolve a inclusão de uma criança com autismo, considerando suas limitações de comunicação e interação, o convívio e acompanhamento para o fortalecimento dos laços são ainda mais relevantes (AGIER, 2011). Observamos, nas narrativas apresentadas, que as redes de apoio nem sempre são constituídas, pois dependem do estabelecimento de laços de parcerias. Quando essas acontecem e laços são ampliados, o trabalho docente passa a contar com apoios que permitem sua execução de maneira mais colaborativa.

\section{Copa do mundo}

As professoras Manu de Educação Física e Rosa, professora polivalente do $5^{\circ}$ ano, narram práticas ocorridas em aulas distintas, com turmas de $5^{\circ}$ ano, no período da manhã, enquanto a professora MC, professora polivalente, atuava no período da tarde com uma turma de $2^{\circ}$ ano.

As três narrativas que apresentamos a seguir estão agrupadas devido ao tema em comum: Copa do Mundo. Elas ocorreram no período do ano em que estavam acontecendo os jogos do torneio, e esse evento mundial passou a fazer parte das aulas de diferentes formas.

Em relação à prática da professora Manu, o assunto Copa do Mundo representou um fluxo trazido pelos estudantes por meio de uma iniciativa durante a aula de Educação Física. A dinâmica da aula propiciou aos estudantes que expusessem seus interesses e seu conhecimento quanto ao tema. A professora, acionando seu 
conhecimento cultural, estabeleceu um diálogo com a turma, ampliando o repertório associado ao assunto, apesar de compreender uma situação inesperada, pois como ela disse, não se tratava de um projeto institucional.

Desenhamos na quadra com giz, a Amarelinha do Brasil, da França, de Portugal, da Espanha. Em vez de colocar o número na amarelinha, colocava o nome do jogador correspondente àquele número de camisa, e a gente fez outros países, porque são países onde os ídolos deles [das crianças] jogam futebol. (Manu)

A situação dessa aula, no entanto, ao ser socializada com a professora Rosa, foi ressignificada, pois passou a dialogar com um projeto desenvolvido pelas três turmas de $5^{\circ}$ ano, O Jornal Mural.

Apesar de não ter sido um projeto institucional da Copa, pensado pela escola toda, por conta do interesse dos alunos, nesta temática, acho que essa atividade da amarelinha da Copa do Mundo, ela foi acrescentada, ela somou ao projeto Mural da Copa, que foi desenvolvido pelos quintos anos. (Manu)

A professora Rosa utilizou-se da motivação que o tema Copa do Mundo gerava na turma e propôs outras atividades que se estenderam às três turmas de $5^{\circ}$ ano da escola e, ainda, de outros professores da escola.

A turma do $5^{\circ}$ ano se envolveu, a gente vê o envolvimento até dos funcionários que estão ali na escola. Nesse jornal mural, quando a gente o faz, a gente procura colocar coisas que também dinamizam as coisas da escola, uma brincadeira, um joguinho, sempre procurando envolver todo mundo com coisas que são consideradas interessantes, como pegadinha, adivinhas, curiosidades. Assim, torna-se um trabalho que não só envolve a turma do $5^{\circ}$ ano, envolve também a curiosidade dos outros alunos, das outras turmas, mesmo porque deixa a escola mais colorida, mais bonita. Eu achei muito bacana a escola ter esse trabalho, novamente. (Rosa)

Sobre essas atividades por meio de projetos entre as turmas, a professora Rosa contextualiza sua realização na escola:

Quando a gente fez esse trabalho, muitas vezes, foi colocada uma mesa do lado de fora da sala, em que a gente conseguia o envolvimento entre as salas, principalmente, no $5^{\circ}$ ano $B$ e $5^{\circ}$ ano $C$. Lógico que a posição física onde nossas salas estavam permitia isso, porque as duas são vizinhas. Assim, esse é um dos principais aspectos positivos para os alunos. (Rosa) 
O cotidiano da escola é muito dinâmico, e frequentemente, os professores têm dificuldade de se encontrar e conversar devido às limitações quanto aos horários e inúmeros compromissos que acumulam (LÉVY, 2003). Nos trechos dessas narrativas, é possível observar que por meio da comunicação entre a professora Manu, socializando brevemente sua aula com a professora Rosa, foi estabelecida a conexão entre as práticas pedagógicas realizadas por ambas, que tiveram continuidade por meio de outras propostas, resultantes da motivação dos estudantes pelo evento da Copa do Mundo.

Em paralelo às práticas do período da manhã, as professoras do período da tarde deparavam-se com o intenso interesse das crianças pelo álbum de figurinhas da Copa. No entanto, poucos possuíam condições de adquiri-las, em face dos recursos econômicos de suas famílias. Essa necessidade de consumo manifestada pelos estudantes e o tema da Copa do Mundo, fortemente divulgado pelas mídias, mobilizou as professoras dos $2^{\circ} \mathrm{s}$ anos a desenvolverem o projeto Álbum de figurinhas da copa. Para executar essa proposta, houve uma mobilização em rede, como indicado por Lima (2015): as professoras, no planejamento e execução de atividades; a gestão, no provimento de recursos; os funcionários, na organização do espaço escolar; os estudantes, que se tornaram os jogadores e foram fotografados. Com isso, as figurinhas foram produzidas e foi possível realizar as trocas de figurinhas.

A principal experiência que eu vivi esse ano e que envolveu a parceria de vários colegas de trabalho foi o projeto do Álbum de figurinhas da Copa. (MC)

Diante do resultado satisfatório do projeto, a professora MC, estimulada por professores da mesma escola e vinculados à Universidade, inscreveu essa prática docente na modalidade de comunicação em um seminário da área. Ao apresentar o trabalho a ouros professores, a especialistas na área, a estudantes e pesquisadores, promoveu a divulgação de seus conhecimentos docentes e adquiriu novos conhecimentos, inquietações e ideias, além de estabelecer laços com os demais participantes do evento (PORTUGAL, 2007). Ao retornar à escola, a professora MC socializou a experiência com suas parceiras de docência, que por sua vez, ressignificaram seu trabalho e demonstraram motivação pelo reconhecimento. 
Eu acho que alguns momentos desse ano, tanto no PNAIC [referindo-se ao Plano Nacional de Alfabetização na Idade Certa] quanto nessas interações com outros colegas de outras redes, eu acho que tudo isso foi enriquecendo o trabalho. Esse trabalho de figurinhas da copa também foi levado ao seminário da XXX, ele foi compartilhado lá com outros pesquisadores, com estudantes de pedagogia. Foi um trabalho, foram aspectos formativos muito importantes na realização desse trabalho, mas eu acho que o principal, mesmo, foi a questão da troca com outros professores. (MC)

Apesar de não ter sido um tema gerador proposto pela instituição escolar, a Copa do Mundo mobilizou várias práticas docentes, pois foi um tema muito divulgado pelas mídias, chegando aos estudantes e professores por diferentes canais de comunicação e gerando conhecimentos, como apresentado por Lévy (2003).

\section{Arte e movimento}

Os participantes Gabi, professora de Educação Física, e Oswaldo, professor de Artes, expõem a parceria que realizaram no decorrer do ano letivo, envolvendo propostas interdisciplinares utilizando práticas circenses, dança, música e movimento. Aproximaram-se por afinidade identitária, pois ambos são professores especialistas. Segundo o professor Oswaldo, eles vivenciam problemas e conflitos semelhantes. Além disso, esse professor havia ingressado nesse ano letivo naquela escola e a professora Gabi, já veterana na instituição, mostrou-se receptiva e estabeleceu laços de confiança com o colega.

Eu acho que o que mais uniu-nos nessa parceria, primeiro, foi pelo fato das duas trabalharem com o movimento, e eu tinha chegado aquele ano na escola. Então, eu queria encontrar alguém com quem eu pudesse dialogar; a gente quer isso, né? Quando a gente está num território novo, buscar com quem a gente pode contar, se enturmar, é normal, como acontece com as crianças. E aí, a Gabi foi superaberta. E eu sempre acabo me aproximando do pessoal da Arte e da Educação Física, porque é onde a gente consegue se encontrar, porque são especialistas. A gente tem uns conflitos que só acontecem com a gente, uns problemas que só acontecem com a gente, então, já rola uma identificação. (Oswaldo)

Apesar de os dois serem especialistas, eram de áreas diferentes, o que complementava as propostas de atividades docentes, que se tornavam interdisciplinares. 
O pessoal da Educação Física também sofre, entre aspas, de ter que trabalhar a dança, dentro da escola. Muitas vezes, até gera um embate entre o pessoal da Educação Física e da dança. Em vez de eu assumir esse embate, procuro fazer parceria, não que eu não vá conseguir, mas é muito melhor trabalhar com outra pessoa, com outro profissional. (Oswaldo)

Além de conhecimentos oriundos de áreas específicas, o professor Oswaldo havia atuado profissionalmente em outras atividades, antes de ingressar na carreira docente. Por isso, ele possuía conhecimentos diferenciados e inovadores sobre dança, circo e atuação artística em diferentes espaços, mas sentia-se inseguro quanto aos aspectos pedagógicos, didáticos e institucionais da escola.

Bom, eu sou formado em dança, bacharel em dança e licenciatura, e antes de atuar na Educação Básica, eu sempre trabalhei com dança, balé e trabalhei muito tempo com tecido acrobático. E quando eu fui para a Educação Básica, um dos meus maiores enfrentamentos era de como trabalhar a dança, trabalhar o circo, trabalhar tudo que eu vinha trabalhando antes, dentro da disciplina de Artes. Isso ainda é um enfrentamento. (Oswaldo)

Nós mostramos vídeos, apresentamos para as crianças alguns compositores, como - Heitor Villa Lobos, [...] cantigas de rodas, que ele fez especialmente para as crianças... [...] Elas puderam apresentar, através da dança, essas músicas. E, no final, nós usamos a música do Caetano Veloso, criando uma coreografia com todas as séries. Nós criamos essa coreografia e pudemos apresentar. (Gabi)

Mais do que o laço estabelecido com a parceira Gabi, o professor Oswaldo narra sobre suas buscas por parceiros que suprissem suas demandas profissionais, na escola e em outros espaços, inclusive o familiar, solicitando apoio do companheiro com quem vive (FIALHO, 2014).

Eu tenho meu companheiro, que ele é músico e que ele me ajuda muito nas aulas de música e percussão corporal. Quando a gente estava trabalhando com dança, quisemos introduzir também as culturas populares, e aí, a gente trouxe o canto, a gente trouxe a percussão corporal. Ele me ajudou muito nessa questão, não só pedagógica, mas na sensibilidade em como abordar com as tais atividades. Acho que somou muito. Mesmo ele não estando presente aqui, durante as minhas aulas, faz parte da escola [porque participa a distância colaborando com as práticas docentes].

Nesses trechos das narrativas apresentadas é possível observar que as parcerias e a constituição de laços fortes (AGIER, 2011), que passam a sensação de confiança e segurança, na realidade do professor, não acontecem exclusivamente no interior da 
escola. Eles existem entre os familiares e grupos de amigos que, quando acionados, podem configurar uma rede de apoio às práticas docentes.

O professor Oswaldo também narra suas buscas por meio de pesquisas na internet, sobre temas específicos da sua área de atuação docente. E a professora Gabi, no decorrer no ano, estabeleceu parcerias fora da escola.

E eu tenho visto algumas referências, coisas que eu vejo na internet, que eu gosto muito e que eu gostaria de trabalhar com as crianças, em relação à instalação [De acordo com o dicionário Houaiss (2001), nas artes plásticas consiste em construção ou empilhamento de materiais, permanente ou temporário, em que o espectador pode participar], performance, que eu acho que dá pra gente trabalhar com eles, também. (Oswaldo)

Eu participei do curso de formação que é realizado no Centro de Formação Municipal com a turma da Educação Física. Esse ano, a gente trabalhou sobre os jogos escolares que aconteceram no final do ano, e também participei do grupo de estudos XXX que acontece na Universidade XXX. (Gabi)

Seja por meio da pesquisa, interagindo pela internet, ou presencialmente em cursos e grupos de estudo, quando o docente se permite estar com o outro desconhecido, para apropriar-se de outras realidades e ampliar o próprio horizonte, uma rede educativa com outras características pode ser constituída, também, por meio de iniciativas como a do professor Oswaldo, que se propôs a pesquisar sobre ideias e temas específicos de sua área. Esse contato com outros interlocutores, que podem ser outros profissionais, instituições ou teóricos, quando acionado, pode ampliar a rede de apoios do professor, repercutindo em sua prática docente, conforme encontrado em Lima (2015).

O professor Oswaldo, em sua atuação profissional, também busca manter uma postura coerente com as memórias que tem sobre sua história de vida e sua formação.

Eu venho da rede pública, também, e eu tenho uma história parecida com a das crianças para quem eu dou aula. Então, eu acho, acho não, né, a Arte, ela me levou para outro mundo, para outra vida. O que eu quero dar para elas é o mesmo que eu tive. (Oswaldo)

Nesse trecho da narrativa, podemos estabelecer um paralelo com o autor Aguiar (2004), que teoriza sobre os processos comunicativos verticais e horizontais. Quando o professor Oswaldo dialoga com as memórias do seu passado nessa 
comunicação vertical, ele elege como parceiras e interlocutoras suas memórias, com as quais estabelece laços afetivos e, ao desenvolver um processo reflexivo, posiciona-se politicamente enquanto professor.

\section{O projeto}

Os excertos da narrativa da professora Aretusa não apresentam relação direta com as narrativas apresentadas anteriormente, pois a experiência pedagógica por ela narrada foi desenvolvida em parceria com professoras da escola que não estão incluídas entre as participantes desta pesquisa.

A participante Aretusa, professora de Arte, manifesta em sua narrativa que entre as parcerias propostas inicialmente para o desenvolvimento do projeto, algumas tiveram mais sucesso que outras, devido a alguns fatores, como tempo e afinidade.

Na realidade, durante a realização desse projeto, apenas a parceria com uma das professoras funcionou bem, fluiu como planejado. Já nas outras, os problemas com o horário e a falta de tempo para sentarmos juntas e revermos algumas questões do projeto atrapalharam o andamento [...]. Essa parceria foi boa, sim, porque facilitou meu trabalho. Além disso, são pessoas com quem eu já fiz outros projetos, outros anos, e isso facilitou bastante a comunicação e a realização do trabalho. (Aretusa)

Eu acho que, para desenvolver um trabalho futuro de parceria, seria complicado se a pessoa tivesse dificuldade de ouvir opiniões diferentes, ela tivesse dificuldades de se dedicar ao projeto, caso não fosse colaborativa (Aretusa).

$\mathrm{Na}$ narrativa da professora Aretusa é possível identificar barreiras que podem dificultar o estabelecimento de parcerias, como falta de tempo, dificuldade na comunicação, sobrecarga de trabalho, bem como características de personalidade. Além disso, por ser uma professora experiente, ela demonstra mais criticidade e seletividade ao se propor um trabalho futuro em parceria.

A professora Aretusa afirma ter participado de cursos de formação durante o ano letivo e que estes repercutiram em suas práticas docentes.

Eu participei de algumas formações durante o ano. Entre elas, eu fiz pós-graduação em psicopedagogia clínica, que repercutiu na minha atuação na escola. [...] Nessa formação, eu aprendi técnicas que me ajudaram em vários momentos críticos, de resolução de problemas na escola com os alunos. (Aretusa) 
Apesar de atuar há 16 anos como professora e ter adquirido repertório na prática docente, em sua narrativa, a professora Aretusa expressa a necessidade permanente de buscar novas parcerias que promovam o desenvolvimento continuado para, da melhor maneira, responder aos desafios dessa profissão.

\section{Discussão}

Inicialmente, esclarecemos que essas narrativas apresentadas não refletem as práticas docentes de todas as professoras dessa escola e nem as características de todas as práticas desenvolvidas pelas professoras participantes desta pesquisa no decorrer de todo o ano letivo. Cada narrativa conta sobre uma prática docente realizada por uma das professoras que aceitou participar do presente estudo.

A partir da análise das narrativas e considerando o perfil dos participantes, observamos que as parcerias sugerem buscas por suprir carências profissionais (ABREU, 2019), como podemos verificar na parceria das professoras Aurora e Keilyan, que juntas buscaram atender às demandas surgidas com a inclusão de um estudante com autismo. A professora Aurora, especialista em Educação Especial com pós-graduação na área, representou para a professora Keilyan, que não possuía a mesma prerrogativa, uma referência de apoio diante do grande desafio enfrentado. Por outro lado, a professora Aurora encontrou na parceira o compromisso, a confiança e a afinidade para a realização do seu trabalho. Ambas se apoiaram emocionalmente diante das dificuldades e inseguranças, pois haviam construído entre si laços de confiança e proximidade.

A complementaridade também é enfatizada na narrativa de Oswaldo, professor novo na escola, que encontrou em Gabi uma parceira de confiança, com quem pode dialogar e compartilhar os desafios pedagógicos e institucionais. Já Gabi encontrou nessa parceria novas possibilidades pedagógicas e interdisciplinares, ampliando seu repertório didático e cultural, além de uma grata amizade (VIGOTSKY, 2007).

A proximidade e a constituição de laços fortes (KAUFMAN, 2012) também podem ser observadas nas demais narrativas: as professoras Any e Joana, que se apoiaram no trabalho com alunos em situação de inclusão nos $1^{\circ}$ s anos, a professora 
MC junto das outras professoras do $2^{\circ}$ ano, no desenvolvimento do projeto Álbum de figurinhas, e a professora Rosa e as outras professoras dos quintos anos, na realização do projeto do Jornal Mural.

As parcerias entre os professores especialistas, devido ao pouco convívio por atuarem em horários distintos dos professores polivalentes e às rotinas diferentes, são menos comuns. Além disso, por não se reconhecerem na rotina e no perfil dos demais professores, indicaram buscar fora da escola parceiros identitários, em cursos ou grupos de formação. A constituição de laços fortes não está, necessariamente, condicionada à territorialidade (LÉVY, 2003), pois os laços fortes podem ser estabelecidos com parceiros distantes fisicamente, principalmente, nesses tempos em que os acessos às tecnologias de comunicação tornaram-se mais rotineiros (FUSER, 2003).

Apesar disso, os laços fortes, aqueles responsáveis pelo sentimento de confiança e segurança, tendem a se desenvolver na escola entre profissionais que convivem intensamente e reconhecem-se como iguais em aspectos identitários (AGIER, 2011). Esses laços, quando estabelecidos, devido à sensação de segurança e comodidade, podem reduzir a disponibilidade para a inovação.

No cotidiano escolar, situações que excedem à capacidade de solução por um profissional, ou mesmo por um grupo, têm sido frequentes, o que gera a desestabilização do equilíbrio e a necessidade da busca pela inovação. Nas narrativas, observamos a busca por soluções diante da ausência de respostas para as questões relacionadas à inclusão, por exemplo. Aurora recorreu aos seus laços fracos, contactando profissionais e pesquisadores dos quais tinha conhecimento, em busca de subsídios. Oswaldo recorreu às pesquisas da internet, ampliando seu repertório de atividades. A Gabi participou de cursos de formação com professores de Educação Física, buscando aproximar-se daqueles que compõem a mesma categoria, em busca de fortalecimento identitário. Esses são alguns exemplos encontrados nas narrativas que demonstraram um fluxo de busca do professor por parceiros que representem potenciais apoios, capazes de sanar as demandas existentes (MONTAÑO; MARTINEZ; TORRES, 2017).

Podemos observar, ainda, nas narrativas analisadas, a constituição de laços e ampliação dos nós nas redes educativas, por meio de vivências dos professores nos espaços sociais que frequentam (FIALHO, 2014). Essa condição pode ser observada 
na narrativa da professora MC, que se propôs a apresentar o trabalho desenvolvido com suas parceiras em um evento acadêmico e, nessa oportunidade, pôde socializar suas práticas com diferentes pessoas reunidas a partir de interesses comuns, que potencialmente poderão vir a ser parceiros importantes em sua rede educativa (PORTUGAL, 2007).

Os parceiros, num sentido amplo, também podem ser interlocutores situados em tempos e espaços diversos dos nossos, com quem dialogamos inclusive internamente (AGUIAR, 2004). Na narrativa do professor Oswaldo é possível observar a relevância dessa parceria ausente fisicamente, mas presente na memória da história de vida desse professor, que diz ter estudado em escola pública e traz consigo o compromisso de retribuir aos seus estudantes as oportunidades que teve por meio da Educação.

\section{Considerações}

Em razão do aqui exposto, das palavras e expressões situadas num contexto escolar observado pela pesquisadora no decorrer do ano letivo, afirmamos que a constituição de redes tecidas em uma escola não se limita ao seu território. Os familiares dos professores e dos estudantes, professores de outras instituições escolares, profissionais de apoio à Educação, pesquisadores, autores de produções científicas e culturais, bem como artistas, também são artesãos dessas redes.

Identificamos representações menos personalizadas, como a Universidade, o Centro de Formação, os Grupos de estudos, os espaços culturais e as mídias. Há, também, aqueles interlocutores, situados na memória afetiva, de formação e profissional do próprio professor.

Observamos nas narrativas que uma das indicações do estabelecimento de parcerias decorre das limitações próprias de uma profissão. Essa incompletude humana mobiliza a busca pelo que o outro possui de diferente, capaz de completá-lo em diferentes aspectos: afetivo/emocional, técnico, acadêmico, cultural, institucional, familiar, legal, pedagógico/didático, identitário, político, reflexivo/dialógico, prático/executor, motivacional e inovador/criativo. 
Com isso, os laços estabelecidos com parceiros, não necessariamente mais próximos no tocante à localização geográfica, caracterizam-se como vínculos afetivos de confiança e estabilidade e configuram-se em laços fortes (AGIER, 2011).

Com outros parceiros, de pouco contato e eventuais trocas, os laços fracos passaram a existir, ou seja, aqueles que podem ser acionados a partir de demandas de fluxos diversificados (KAUFMAN, 2012).

Há, ainda, a ausência de laços, que pode decorrer da falha no processo comunicativo, impossibilitando a circulação de fluxos entre alguns possíveis parceiros. Da mesma forma, são identificados laços interrompidos, devido a barreiras do cotidiano, como falta de tempo ou desencontros de interesses ou necessidades. E outros, ainda, surgidos espontaneamente a partir de afinidades entre os parceiros, ou induzidos, para atender a uma demanda latente do cotidiano.

Considerando a análise realizada, inferimos que participar de atividades coletivas, que promovam a socialização com interlocutores desconhecidos ou afastados, seja em cursos diversos, seja em espaços culturais, associações, pesquisas, pode contribuir com a ampliação das redes educativas e diversificar os laços e apoios disponíveis ao professor, permitindo-lhe elaborar práticas que extrapolem a zona de conforto e mantenham-se vivas e dinâmicas como a realidade das escolas.

\section{Referências}

ABREU, M. das G. dos S. Experiências Formativas na licenciatura em Matemática: perspectivas e contribuições. 2017. 166 p. Orientadora: Maria Auxiliadora Bueno Andrade Megid. Tese (Doutorado em Educação) — Pontifícia Universidade Católica de Campinas, Campinas, 2019.

AGIER, M. Antropologia da cidade: lugares, situações, movimentos. São Paulo: Terceiro Nome, 2011.

AGUIAR, V. T. de. O verbal e o não verbal. São Paulo: UNESP, 2004.

ALMEIDA, A. R.; MEGID, M. A. B. A. A escrita colaborativa na formação continuada de professores que ensinam matemática. Inter-Ação, Goiânia, v. 42, n. 1, p. 176-193, jan./abr. 2017.

ALVES, N. G. Formação de docente e currículos para além da resistência. Revista Brasileira de Educação, Rio de Janeiro, v. 22, n. 71, e227147, out. 2017.

ALVES MAZZOTTI, A. J. O método nas ciências naturais e sociais: pesquisa quantitativa e qualitativa. São Paulo: Pioneira, 1998.

AZEREDO, J. C. de. Gramática Honaiss da Lingua Portuguesa. São Paulo: Publifolha, 2011. 
CAPRA, F. A visão sistêmica da vida: uma concepção unificada e suas implicações filosóficas, políticas, sociais e econômicas. Trad. Mayra Leruya Eichemberg, Newton Roberval Eichemberg. São Paulo: Cultrix, 2014.

CASTELLS, M. A sociedade em rede. Trad. Roneide Venancio Majer. 17. ed. São Paulo: Paz e Terra, 2016.

CLANDININ, D. J., CONNELLY, F. M. Pesquisa narrativa: experiências e história em pesquisa qualitativa. Trad. Grupo de Pesquisa Narrativa e Educação de Professores. ILEEL/UFU. Uberlândia: EDUFU, 2011.

CUNHA, M. I. da. Conta-me agora!: As narrativas como alternativas pedagógicas na pesquisa e no ensino. Rev. Fac. Educ. São Paulo, v. 23, n. 1-2, jan. 1997.

HOUAISS, A. Dicionário Honaiss. Instituto Antônio Houaiss. [S.l.]: Editora Objetiva, 2001.

DUTRA, E. Narrativa como uma técnica de pesquisa fenomenológica. Estudos de Psicologia, Natal, v. 7, n. 2, p. 371-378, 2002.

FIALHO, J. M. R. Análise de redes sociais: princípios, linguagem e estratégias de ação na gestão do conhecimento. Perspectivas em Gestão e Conhecimento, João Pessoa, v. 4, p. 9-26, out. 2014.

FIORENTINI, D.; FREITAS, M. T. M. As possibilidades formativas e investigativas da narrativa em educação matemática. Horiz̧ontes, v. 25, n. 1, p. 63-71, jan./jun. 2007.

FUSER, B. Sociedade em rede: perspectivas de poder no espaço virtual. Transinformação, Campinas, v. 15, Edição Especial, p. 117-128, set./dez. 2003.

GALVÃO, C. Narrativas em educação. Ciência e Educação, v. 11, n.2, p. 327-345, 2005.

GIL, A. C. Métodos e técnicas de pesquisa social. 6. ed. São Paulo: Atlas, 2008.

JOSSO, M.-C. Experiências de vida e formação. São Paulo: Cortez, 2004.

KAUFMAN, D. A força dos "laços fracos" de Mark Granovetter no ambiente do ciberespaço. Galáxia. São Paulo, n. 23, p. 207-218, jun. 2012.

LÉVY, P. A inteligência coletiva: por uma antropologia do ciberespaço. 4. ed. São Paulo: Loyola, 2003.

LÉVY, P. Cibercultura. São Paulo: Editora 34, 2008.

LIMA, J. Á. de. A ação educativa em rede: obstáculos e recomendações. Educação, Sociedade e Cultura, p. 9-29, 2015.

MONTAÑO, M. J. N.; MARTINEZ, A. L.; TORRE, M. E. H. El trabajo colaborativo em red impulsor del desarrollo profesional del profesorado. Revista Brasileira de Educação, v. 22, n. 70, jul./set. 2017.

MORIN, E. Introdução ao pensamento complexo. Trad. Dulce Matos. 5. ed. Lisboa: Instituto Piaget, 2008.

PASSOS, C. L. B. Processos de formação de professores: narrativas, grupo colaborativo e mentoria. São Carlos: EdUFSCAR, 2010. 
PORTUGAL, S. Contributos para uma discussão do conceito de rede na teoria sociológica. Portugal: Universidade de Coimbra, 2007. (Oficina do CES, n. 271).

RODRIGUES, N. C.; PRADO, G. de V. T. Investigação Narrativa: construindo novos sentidos na pesquisa qualitativa em educação. Revista Lusófana de Educação, v. 29, n. 29, p. 89103, abr. 2015.

VIGOTSKY, L. S. A formação social da mente: o desenvolvimento dos processos psicológicos superiores. Trad. José Cipolla Neto, Luís Silveira Menna Barreto, Solange Castro Afeche. 7. ed. São Paulo: Martins Fontes, 2007.

XAVIER, A. C. Leitura, texto e hipertexto. In: MARCUSCHI, L. A.; XAVIER A. C. (orgs.). Hipertextos e Gêneros Digitais. 2. ed. Rio de Janeiro: Lucerna, 2005. 